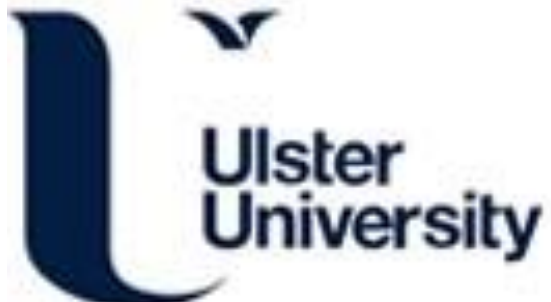

\section{'People have a knack of making you feel excluded if they catch on to your difference': Transgender experiences of exclusion in sport.}

Hargie, O., Mitchell, D., \& Somerville, I. (2015). 'People have a knack of making you feel excluded if they catch on to your difference': Transgender experiences of exclusion in sport. International Review for the Sociology of Sport., Online. https://doi.org/10.1177/1012690215583283

Link to publication record in Ulster University Research Portal

\section{Published in:}

International Review for the Sociology of Sport.

Publication Status:

Published (in print/issue): 22/04/2015

DOI:

$10.1177 / 1012690215583283$

\section{Document Version}

Author Accepted version

\section{General rights}

Copyright for the publications made accessible via Ulster University's Research Portal is retained by the author(s) and / or other copyright owners and it is a condition of accessing these publications that users recognise and abide by the legal requirements associated with these rights.

\section{Take down policy}

The Research Portal is Ulster University's institutional repository that provides access to Ulster's research outputs. Every effort has been made to ensure that content in the Research Portal does not infringe any person's rights, or applicable UK laws. If you discover content in the Research Portal that you believe breaches copyright or violates any law, please contact pure-support@ulster.ac.uk. 
Hargie O., Mitchell, D. and Somerville, I.

'People have a knack of making you feel excluded if they catch on to your difference':

Transgender experiences of exclusion in sport.

\section{Owen DW Hargie}

School of Communication, University of Ulster, UK.

\section{David H Mitchell}

Irish School of Ecumenics, Trinity College Dublin at Belfast, UK.

\section{Ian JA Somerville}

Media and Communication, University of Leicester, UK.

Citation: Hargie O., Mitchell, D. and Somerville, I. (online first 2015) 'People have a knack of making you feel excluded if they catch on to your difference': Transgender experiences of exclusion in sport, International Review for the Sociology of Sport 
Hargie O., Mitchell, D. and Somerville, I.

\begin{abstract}
While there is a growing literature in the field of gender, sexuality and sport, there is a dearth of research into the lived experiences of transgender people in sport. The present study addresses this research gap by exploring and analysing the narratives of transgender people in relation to their experiences of sport and physical activity. These narratives are examined within the theoretical rubrics of social exclusion and minority stress theory. The findings from in-depth interviews with ten transgender persons are detailed. Four interconnected themes emerged from the interviewee accounts: the intimidating nature of the changing/locker room environment; the impact of alienating sports experiences at school; the fear of public space and how this drastically constrained their ability to engage in sport and physical activity; and, the overall effects of being denied the social, health and well-being aspects of sport. The findings are discussed in relation to the distinctive quality of transgender exclusion, and the related distal and proximal stressors experienced by this particular minority group.
\end{abstract}

\title{
Keywords
}

Transgender people, LGBT, sport, social exclusion, minority stress theory. 
Hargie O., Mitchell, D. and Somerville, I.

\section{Introduction}

The intersection of gender, sexuality and sport has produced voluminous empirical research and theoretical reflection (for example, Caudwell and Browne, 2013; Hargreaves and Anderson, 2014; Scraton and Flintoff, 2002). The practical, political and philosophical issues surrounding transgender participation in sport are increasingly being recognised. A small number of qualitative studies, situated in queer and gender theory, have examined the sports experiences of individuals who do not neatly fit into the two-sex binary (Caudwell, 2014; Lucas-Carr and Krane, 2011, 2012; Semerjian and Cohen, 2006; Travers, 2006; Travers and Deri, 2011; Tagg, 2012). However, much of the research on transgender people and sport focuses upon issues related to gender testing and regulations regarding competitive and elite sport (Buzuvis, 2011; Reeser, 2005; Sullivan, 2011; Symons and Hemphill, 2006; Wahlert and Fiester, 2012). Overall while the literature reveals some progress toward greater inclusivity for transgender people in relation to sport (Buzuviz, 2011; Hargreaves and Anderson, 2014), it is fair to say that both the public understanding of, and policy responses to, transgender issues remain in their infancy. General acknowledgment of barriers to transgender participation is yet to be enriched with deeper understanding of how transgender people experience sport and physical activity.

The present research helps to redress this deficit. It is concerned with the role of sport as an everyday agent of social inclusion and exclusion in the lives of transgender people. While the links between sport and social exclusion have emerged as a key topic of academic enquiry and policy concern (Collins and Kay, 2014; Spaaij, Magee and Jeanes, 2014), the role of sport in facilitating or inhibiting the social participation of transgender people has featured little. The research detailed here formed part of a major Northern Ireland Government funded research project by the authors, on social exclusion and sport. This paper 
Hargie O., Mitchell, D. and Somerville, I.

focuses upon findings pertaining to the nature and impact of exclusion as experienced by transgender people.

Transgender people, sport and social exclusion

'Transgender' is regarded as an 'umbrella term for people whose gender identity and/or gender expression differs from what is typically associated with the sex they were assigned at birth' (GLAAD, 2014: 14). Not all transgender identifying individuals aspire to physical transition; Travers (2006) describes 'gender conformers' and 'gender transformers'. The former exhibit a conservative and essentialist view of gender, feeling they are 'trapped in the wrong body' and desiring hormonal and surgical alteration to realise their identity. They wish to fit into the two-sex binary. By contrast, 'gender transformers' reject the binary, preferring to view gender as a continuum. They eschew fixed categorisation and do not feel the need to undergo physical transformation.

The gender conformist challenge, then, is less radical, and, in sport, may be accommodated by policies such as the International Olympic Committee's Stockholm Consensus (2004) which allows for the participation of transgender athletes who can medically verify that they have completed the physical gender reassignment process (Cavanagh and Sykes, 2006). But from a transformer perspective, such policies simply reinforce the two-sex binary and the dubious assumption that all women require protection from unfair disadvantage through segregation from men in sport, and ignore cultural, economic and racial inequality in access to gender reassignment surgery (Love, 2014; Sullivan, 2011; Sykes, 2006). Caudwell (2014: 402) is skeptical of the conformer/transformer categorization, suggesting 'it lacks the incompleteness that often accompanies people's lived experiences of gender'. Yet the participants in the present study, at least, quite clearly aspired to or had attained physical transition and passionately wished to 'blend in' and be accepted as 
Hargie O., Mitchell, D. and Somerville, I.

the sex other than their physical sex at birth - they were gender conformers. The findings of this study will show that both gender conforming and gender transforming aspirations pose a significant challenge to the gendered organisation and culture prevalent in the sporting world and beyond it.

Systemic segregation based upon conventional notions of gender and sexuality, with designated exclusionary identity groups, has long been part of the organisational and cultural fabric of sport. Thus, Symons, Sbaraglia, Hillier and Mitchell (2010: 7) noted that, 'sexuality is mostly coded as heterosexuality and there is little positive room for alternate sexualities. Generally, transgression from these norms around gender and sexuality is punished in sport'. The rigid division of sport into male or female, based upon bio-genetic sex differences, would seem to have been driven by an ideological and political heterosexual imperative that privileges masculinity (Brackenridge, Alldred, Jarvis, Maddocks, and Rivers, 2008). Most sports have therefore traditionally tended to be 'heteronormative': exclusively legitimising and reinforcing heterosexuality (Kauer and Krane, 2013). The imposition of a deterministic gender bifurcation makes it especially difficult for those who fall outside of the perceived 'normality', such as transgender people, to live their true gender identities when participating in formal sports activities (Sykes, 2011).

The experiences of transgender people in sport reflect the wider problems that they face in society. For example, Meyer (2003) developed a minority stress model based upon evidence that LGB individuals suffer from additional social stress over and above the rest of the population, in the form of stigma and prejudice due to their minority position, and that this in turn causes an increase in mental disorders. He distinguished between distal stressors that are external to the person, such as prejudice and discrimination, and proximal stressors which are internal processes related to distal stressors, including the fear of experiencing negative events and related preventive vigilance, rumination on negative experiences of 
Hargie O., Mitchell, D. and Somerville, I.

prejudice, internalisation of negative social attitudes about one's minority group, rejection sensitivity and related attempts to conceal one's minority identity. Minority stress theory purports that these added distal and proximal stressors cause problems for the individual in coping with their everyday lives and so result in impairments in health. There is supporting evidence that this is the case. In their recent review of social stress theories, Le Blanc, Frost and Wight, (2015: 44) conclude that "The existing research supports minority stress theory, consistently demonstrating significant relationships between minority stress experience and mental health".

In terms of research into transgender people that uses this theory, a recent study of college students' experiences in the United States revealed that transgender students, compared to men or women in the sample, had more negative perceptions of college climate, reported higher levels of harassment, were more likely to have considered leaving college, feared more for their safety, and were reluctant to disclose their gender identity owing to the possibility of negative consequences and intimidation (Rankin et al., 2010). Other studies have shown that lesbian, gay, bisexual (LGB) and transgender people suffer from a wide range of health problems and are at higher risk of experiencing distal stressors, because they face elevated rates of discrimination and violence (Meyer and Northridge, 2007). They also experience increased rates of psychological distress (Effrig, Bieschke, and Locke, 2011) as well as attempted suicide and suicide ideation (Grossman and D’Augelli, 2007; Kenagy, 2005; Mathy, 2002). The present study will investigate the extent to which such stressors are present when transgender people participate in sport and physical activity, and the degree to which these distal and proximal stressors act as exclusionary forces to involvement.

The experiences, emotions, needs and difficulties of transgender people in sport remain poorly understood. As Symons et al. (2010: 59) stress, there is a need for 'more substantial research of these [transgender] experiences' in sport. Guidelines on transgender 
Hargie O., Mitchell, D. and Somerville, I.

inclusion for national sports governing bodies published by the UK Sports Councils acknowledge that this was a response to the widespread confusion, misunderstanding and ignorance within the sports community on how to handle transgender issues (Sports Council Equality Group, 2013). Transgender people are usually subsumed within a single LGBT collective and so most research has been incorporated within this frame (Caudwell, 2014; Lucas-Carr and Krane, 2011). Nevertheless, some studies have shed light on ordinary, nonathlete transgender experiences of sport.

For example, research in London (Whittle, Turner and Al-Alami, 2007) found that almost one half of respondents would not use sports centres due to concerns that they would not be permitted to utilise changing or locker rooms reflective of their acquired gender; indeed, 6.5 per cent said they had actually been instructed to use changing rooms or toilets contrary to their true gender. These findings were supported by the results of another London survey which confirmed that transgender people were reluctant to use their local sporting facilities owing largely to problems with toilet and changing areas (Keogh, Reid and Weatherburn, 2006). This issue is reflective of what Halberstam (1998) termed 'the bathroom problem' as a central concern of transgender people in public spaces, because it is here that they frequently encounter fellow citizens who regard them as 'having violated a cardinal rule of gender: one must be readable at a glance' (p. 23). It would seem that 'the bathroom problem' becomes 'the changing room problem' whenever a transgender person attempts to participate in sport. Keogh et al. (2006) found a further problem related to concerns surrounding the binary gender nature of sports activities and related expectations therein, since 'fitness classes etc. are often single gender and trans people fear the reception they will get if they enrol' (p. 38). Indeed, a survey of the sports experiences of transgender people in Scotland revealed that some 80 per cent of respondents had experienced or witnessed transphobic or homophobic abuse in sport (Smith, Cuthbertson and Gale, 2012). 
Hargie O., Mitchell, D. and Somerville, I.

Furthermore, a number of interesting small-scale qualitative studies have also examined transgender persons' experiences within sport (Caudwell, 2014; Lucas-Carr and Krane, 2012; Semerjian and Cohen, 2006; Travers, 2006; Travers and Deri, 2011; Tagg, 2012). Situated, in the main, in queer/feminist theory, these studies have been preoccupied with how transgender individuals experience and express their gender identities in specific sporting contexts such as lesbian softball leagues, school and university sport, or men's netball. This article builds on this work, but takes a slightly different focus, interrogating how a sample of transgender people, with varying degrees of interest in sport and physical activity and at different stages of transition, encounter obstacles to participation in sport and physical activity, and the impact that these obstacles have. As such, this study takes its cue primarily from research such as Collins and Kay (2014) and Spaaij et al. (2014) who have examined the impact of processes of social exclusion on participation in sport, and the impact of exclusion from sport on the socially excluded groups.

Social exclusion has attracted considerable research and debate, especially in relation to its relevance for government policy (von Braun and Gatweiler, 2014). Numerous reviews of the evolution and meaning of the term exist (e.g. Barnes, 2005; Burchardt, LeGrand and Piachaud, 2002a; Pierson, 2010; Spaaij et al., 2014). They all concur that while social exclusion is closely linked to poverty it also has other defining features. Thus, one influential definition is that: 'An individual is socially excluded if he or she does not participate in key activities of the society in which he or she lives' (Burchardt, LeGrand and Piachaud, 2002b: 30). The four key activities identified by these authors are: social interaction (having close relationships with family, friends and the wider community -including engagement in activities such as sports); production (being employed); consumption (purchasing power); and political engagement (being able to participate in local or national governance). Silver and Miller (2003) further capture the complexity and elasticity of the concept through their 
Hargie O., Mitchell, D. and Somerville, I.

delineation of five key features of social exclusion. It is: multidimensional, involving a range of interconnected factors; relative and varying across contexts; dynamic, since it spans a continuum from complete exclusion to full integration; relational, in that it incorporates facets such as lack of participation, rejection, and isolation; and, active, since someone or something causes the exclusion. Social exclusion thus encapsulates the psychological effects of being isolated from or rejected by others through, for example, prejudice or discrimination (Abrams, Hogg and Marques, 2005). In this way, it 'incorporates non-material states and processes of disadvantage, including those created through others' opinions' (Tunstall, 2011: $3)$.

The relationship between social exclusion and sport has attracted the attention of researchers and policy makers in recent decades. A voluminous body of research has emerged that examines the specific barriers to sports participation faced by marginalised groups, especially poorer people, females, older people, people with disabilities, ethnic minorities and LGB and transgender people (e.g. Collins and Kay, 2014; Dagkas and Armour, 2012; Dionigi, 2006; Federico, Falese, Marandola and Capelli, 2013; Hargie, Somerville and Mitchell, 2015; Smith et al., 2012; Spaaij et al., 2014; Stalsberg and Pedersen, 2010). At the same time, sport is widely viewed as having the capacity to help combat social exclusion/promote social inclusion. As Coalter (2007) notes, arguments for the social benefits of sport are based on the presumption that these will have a broader influence through changed behaviour and attitudes, leading to stronger community identity, social coherence and integration i.e. social capital.

But social capital has a well-known 'dark side', potentially excluding outsiders from insiders' privileges (Putnam, 2000), and sports clubs can perform this negative function (Coalter, 2007; Lake, 2013). Moreover, evidence for the positive social impact of sport is uncertain in large part due to the difficulty of proving a causal connection between sports 
Hargie O., Mitchell, D. and Somerville, I.

participation and changed attitudes or behaviour (Coalter, 2007). However, at the very least, the capacity of sport and physical activity to contribute to personal health, wellbeing and enjoyment is universally recognised and thus we approach this study on the basis that the widest possible access to sport and physical activity is desirable.

In this study we set out to examine the stressors linked to sports exclusion in the context of Bailey's (2005) four connected dimensions of social inclusion, namely: spatial, in that participation reduces social and economic distances between groups; relational, in terms of fostering a sense of acceptance and belonging; functional, through increasing knowledge, understanding and skill; and, power, in terms of enhancing a sense of personal control. Sport has the capacity to develop all of these by bringing together individuals from differing backgrounds to share activities (spatial), fostering and creating a sense of togetherness and belonging - e.g. to a club or team (relational), offering the potential to develop fitness and acquire valued skills (functional), and extending one's existing networks (power). The corollary of this is that those who are excluded from sport may lose out on the valuable potential to develop along these four domains. In our research we explored whether this is the case with transgender people.

\section{Methodology}

Our sample was 10 self-identified transgender people, 6 females and 4 males, with ages ranging between 25 and 62 years. Participants were recruited through Focus: The Identity Trust, a support group in Belfast, Northern Ireland, for those who have been referred from a gender identity clinic or registered medical practitioner. All interviewees were living as their desired gender, though not all had undergone physical transition; as noted above, they would be regarded as 'gender conforming' (Travers, 2006). Some believed they could 'pass' in 
Hargie O., Mitchell, D. and Somerville, I.

their preferred gender more than others, but all felt some degree of insecurity in their gender presentation. More information on each interviewee is given below as appropriate.

Prior to the interviews taking place at Ulster University, a member of the research team met with two leaders from the support group to explain the research goals and secure their participation. In line with the University's ethical approval process, interviewees completed and signed written consent forms. Semi-structured interviewing was employed in order to discover participants' interests in sport, experiences of inclusion/exclusion in sport and physical activity through the life course, and their emotions and aspirations that attended sport and physical activity. Interviews lasted between 30 minutes and one hour. While we acknowledge that transgender identity is far from being the only factor in a transgender person's ability and inclination to take part in sport and physical activity (gender, class, ethnicity, personality etc. are also salient), the impact of transgender status was the focus of this study. Interviews were transcribed for analysis which was inductive in nature, with themes emerging from data. This involved the process of 'close reading' wherein a detailed reading and re-reading of the text is conducted (Alvesson and Skoldberg, 2009). Using NVivo software, exclusion/inclusion themes were identified and detailed examples of each were compiled.

When describing a transgender person 'it is best to ask which term an individual prefers' (GLAAD, 2014; 15). All of the participants in this study stated that they were comfortable with either male/female, or trans man/trans woman. For the purposes of clarity, we use the terms trans woman and trans man throughout. The names of all participants have been changed to ensure anonymity; each pseudonym reflects the interviewee's preferred gender.

\section{Results and analysis}


Hargie O., Mitchell, D. and Somerville, I.

From the accounts of this group, four main interconnected themes emerged. These were: problems experienced when using changing rooms; negative sports experiences at school; the difficulties of appearing in public; and, the impact of their exclusion from sport.

\section{'You're neither one nor the other': The changing room problem}

In line with previous findings (Keogh et al., 2006; Whittle, et al., 2007), discomfort with communal changing rooms/showers was by far the greatest barrier to respondents taking part in sport. This study built upon extant research by identifying the specific reasons for this discomfort. Three main sub-themes emerged. Firstly, in terms of minority stress theory, locker rooms created definite stressors for the interviewees. There was a strong sense of anxiety about using the changing rooms of the 'other' gender. Given that changing areas are spaces strongly associated with distinct gendered behaviour, participants had no experience or expertise in what was acceptable behaviour therein. There was a sense of 'mystery' and fear of the unknown surrounding them and a lack of sub-cultural expertise of the unspoken locker room etiquette. As expressed by Paul: 'We've never been socialised in them...we'd still feel uncomfortable going in there because we've never, we've never had that like. The guys changing rooms at school you know, we've never experienced that'. Post-transition, with his physicality and gender identity finally aligned, Paul desired to fit in to the masculinised culture of the male locker room, yet fear of rejection due to his transgender history acted as a strong disincentive to placing himself in that situation.

Secondly, respondents were also acutely sensitive to how their presence in changing rooms could have an adverse effect on other people - that it may actually 'violate' them. Interviewees explained that during transition the physical issue of gender appearance and related concerns regarding attire, prosthetics etc. resulted in a heightened fear of the possibility of experiencing negative events, related anxieties about rejection, and increased 
Hargie O., Mitchell, D. and Somerville, I.

preventive vigilance with regard to being 'exposed'. But they also expressed the view that undressing in communal changing rooms could cause discomfort or shock in others responses which the interviewees wished to avoid. Indeed, some expressed the view that it was wrong for them to use the communal changing room. Thus, Paul pointed out that: 'I got to the stage I wouldn't, couldn't go to the gym anymore because I felt I was violating everybody else in the changing room 'cause I'm a guy and like everybody else is a woman'. His internal conditioning of 'maleness' was such that he found being around women in the intimacy of the changing room, despite then visibly being a woman, to be an insurmountable barrier, eliciting unwanted feelings of guilt and transgression. This indicated both an internalisation of negative social attitudes about his minority group and a clear attempt to conceal his minority identity.

A third barrier was if the person had not yet transitioned and was required to use the changing room of their natal sex, they felt that by being forced to reject their true identity they were then discriminated against and 'effectively excluded'. This was explained by Colin, who had been living as a man for several years but had yet to undergo physical transition: 'The biggest issue was changing. You know, because before that I was attempting to be someone that I never was. But once you actually made the decision that you can't do that anymore, then you are effectively excluded because you're neither one nor the other.' He also described the feeling of being caught 'in between' provoked by the changing situation: 'Even at school if I was getting changed with lots of girls it was embarrassing because I knew I didn't have the body I wanted to have, and at the minute I'm looking at guys and going, "right, that's the body I want to have but I don't have it". I just want to leave.'

Since, like bathrooms, locker rooms are a crucial site for the social policing of the gender binary (Halberstam, 1998), it is no surprise that our interviewees unanimously agreed that locker rooms and showers should consist entirely of individual cubicles. They felt that 
Hargie O., Mitchell, D. and Somerville, I.

all-cubicle changing rooms would reduce the stress they experienced and ensure that transgender people did not draw attention to themselves as at present. They also believed that it would protect other users from experiencing unease at encountering them in the changing area.

\section{'Why am I not over there?’ Negative sports experiences at school}

The role of school sport in reproducing gender stereotypes and excluding people who do not fit or identify with those stereotypes is well known (Clark and Paechter, 2007; Sykes, 2011; Dagkas and Armour, 2012). This research confirmed these findings and elucidated them in detail for transgender people. School sports invoked particularly acute feelings of gender discrepancy in respondents who ruminated about their experiences at length. As stated by Paul, 'I was friends with all the boys and I was going, why am I not over there? And I kept getting put over here with this lot and you know it's just not right.' From the analysis, two sub-themes emerged.

Firstly, some developed an alienation from team sports. Given how team sports are often dominated by expectations of stereotypically masculine behaviour (Anderson, 2013), this was a specific problem for the trans women interviewees. The depth of abhorrence engendered by the experience was exemplified by Sandra (aged 20-30) who expressed the stark view that, 'It felt like going to a concentration camp when I had to do PE'. For some, their alienation from team games turned them towards individual sporting activities. Mary explained how she felt both less fear of gender exposure and a sense of being able to be oneself when competing individually: 'The first time that I ever felt comfortable in a sport was athletics and that's because it was individual and I could be me in here and no one could guess, you know, what's going on inside.' Individual sport, decoupled from expectations of 
Hargie O., Mitchell, D. and Somerville, I.

body 'normality' or gendered performance, reduced her stress by offering her a safe medium through which to express her sporting identity.

A second sub-theme was the central role played by teachers in shaping and enforcing a stressful and exclusionary sports environment, while taking no cognisance of the possible presence of gender difference among pupils. As expressed by Sandra: 'Teachers exclude you in a way when you're younger, because they're like "Oh you're useless at this" or, or they try and force you to do a sport or force you to do PE.' Similarly, Joanne, who had attended school in the 1960s and 1970s, recalled: 'One of my very early memories from school is asking the Headmaster if I could play netball with the girls rather than football with the boys and it was met with a rather curt refusal, a very intense refusal. That established very early on in my life that what I was feeling inside was wrong.' These testimonies resonate with previous research on how taken-for-granted, hegemonic discourses regarding physical athleticism and attractiveness, heteronormativity, and masculinity act to marginalise many young people in physical education, stifling confidence in their sporting ability (Sykes, 2011). Given the powerful socialising role of school, failure to be accepted in school sports cultures has the capacity to engrain wider perceptions of rejection, inadequacy and even, as Joanne suggested, guilt.

\section{'It becomes this massive thing': Recreation and appearing in public}

It may be thought that transgender people could at least more readily participate in physical activity pursuits that do not require using shared facilities, or partaking in gender segregated activities, but the interviewee accounts show that this is not the case. Again, three explanatory sub-themes emerged. The first was that feelings of fear and marginalisation were engendered by simply venturing out in public. This radically restricted the range of activities available to them. For example, on a walk at a well-known area of scenic beauty one of the 
Hargie O., Mitchell, D. and Somerville, I.

participants had recently been verbally abused by a group of people. Interviewees highlighted the large amount of forward-planning required for any outing, careful selection of routes, possible dangers that could be encountered, and the related stress that they often felt even in contemplating it.

A second sub-theme was a strong sense of rejection sensitivity about being recognised, publicly outed, and subsequently treated differently. Thus Conor said: 'The thing about going to public swimming pools or sports, somebody I know could be down there, I don't particularly want them to know, you know.' Anne discussed in some detail how the prospect of any public outing with her child was severely tempered by the very real fear of exposure since the child called her 'daddy', and this would create difficulties if overheard by others. The third sub-theme was the unwillingness to socialise in public as a group due to the belief that being together made their difference more conspicuous. One reason for this was labelling confirmation, as explained by Roger: 'They could maybe go, "is she or isn't she?" But if she's with someone else, they go, "oh they are". That confirms it.' They would only feel comfortable going out with other transgender people if there was no fear of recognition, and they felt anonymous and hence safe. Fear of antipathy and being made to feel overtly excluded by fellow spectators also made participants very loath to attend sporting events, since: 'People have a knack of making you feel excluded if they catch on to your difference, they pull their child away like you're a sex offender or something' (Sandra). The perceived likelihood of being stigmatised for violating gender expectations in such a setting is a decisive constraint on entering such a space.

\section{'Suffering the humiliation': The impact of sports exclusion}

Transgender people are in essence placed in a 'Catch 22' situation by the demands of the transitioning process. They are required to live as their desired gender for two years in order 
Hargie O., Mitchell, D. and Somerville, I.

to 'prove' themselves, before physical changes - hormones, surgery - take place (see Hansson and Dupret 2007, for an explanation of this process in Northern Ireland), yet the risk of embarrassment, public complaints, or being banned by staff, make this extremely stressful. Indeed, interviewees said that the challenges of the two-year transition period, and the expectation that other people would be uncomfortable and perhaps hostile if their transgender status was revealed, meant that they often simply withdrew from many activities, including sport and exercise. Thus, while research by Smith et al. (2012) identified transphobia as prevalent in sport, actual experiences of transphobia in sport (as opposed to the fear of transphobia) was not a major theme in our research because the main method used by interviewees to reduce stressors was to self-exclude.

Nevertheless, Danielle, who lived and presented as a woman but had not yet physically transitioned, did report that she had been asked to leave her dancing class after she made it known to people that she would be attending as a woman in future. Being forced to give up an activity that she had pursued for 14 years was not only a painful experience, but provoked intense anxiety about how she should respond to this situation. She explained: 'People are saying, “Go for it. If people can't handle you, that's their problem”. But they're not me. They're not the ones standing there when someone's saying, "Sorry I'm going to have to ask you to leave the class". They're not the one suffering the humiliation.' Clearly, the psychological capacity of a transgender person to endure and navigate such a distressing situation is a key variable in whether they are able participate in sport.

Interviewees keenly felt the absence of what they believed to be the social, health and wellbeing benefits associated with participation in sport. Respondents felt they suffered physical and mental health problems as a result of this exclusion. They pointed out that it is important to be in good physical shape for transition surgery and this can be difficult without options for exercise. They were caught in a vicious circle: having to cope with the 
psychological stress of gender transition; being forced to withdraw from sport/exercise during the transition process; suffering lower levels of fitness; and, so experiencing increased levels of stress: 'Most of us would want to do sport. And it would be the best thing for us, particularly in that difficult stage [transition] you know. Yeah, you know our life experience really makes us anxious and depressed and the best thing for that is exercise' (Roger).

Their exclusion from sport also had negative social and psychological costs in terms of socialising and forming relationships. Paul cited his fear of accepting invitations to play sports with non-transgender work colleagues for two reasons. Firstly, he worried that he may be 'discovered' as transgender and suffer as a result. Secondly, he was aware that his sporting ability would be much lower than the others because he had not played for so long and so: 'it would really mark you out'. His interpretation chimes with Caudwell's (2014) research which found that transgender men, despite leaving 'femaleness' behind, still feel alienated by 'normal' male sporting cultures where masculinity is associated with athletic ability, transphobia and heteronormativity. Spaaij et al. (2014) note that total sports exclusion is rare; marginalised groups who feel rejected in mainstream sports may choose alternative sports settings such as ethnic minority leagues and gay or lesbian sports clubs and leagues, which can be inclusive of transgender people (Travers and Deri, 2011). But the severity of the obstacles facing the transgender participants in our study meant that this was not an option. For example, Mary, who had recently undergone gender reassignment surgery, pointed out that she could never envisage their group being able to book a pitch to play five-a-side football because of their visible difference as a group.

A final issue here was the financial dimension to transgender sports exclusion. Their lower income levels and the increased costs associated with transitioning meant that sporting opportunities were reduced. Danielle commented: 'we tend to get very low paid jobs if we're lucky enough to get a job at all...so my disposable income to even partake of sports and 
Hargie O., Mitchell, D. and Somerville, I.

things is a lot lower than it would be.' Interviewees also mentioned the increased expense of make-up and certain prosthetics they required, leading Joanne to conclude: 'There's more important things to be spending your money on than sports'.

\section{Discussion}

As noted above, the interviewees were 'gender conforming' and as such, experienced a heady mix of alienation from gender-segregated sport and physical activity on the one hand and desire to fit into such segregation on the other. For gender conforming individuals, legal recognition and physical transition in theory hold out the possibility of full sports inclusion not the case for gender transformers who reject categorisation and physical and gender unambiguousness. Yet the interviews nevertheless demonstrate the multiple obstacles facing gender conformers in sport.

The pattern of causes and impacts of sports exclusion illustrated how the sense of being different was confirmed and indeed heightened by early school experiences. The normative gender expectations of stereotypical male and female behaviour, as enforced by teachers and expected by peers, evoked a mixture of emotions linked to sport, including fear, alienation, loathing and exclusion. In adult life, they then found themselves on the sidelines of the sporting world, in which aspects such as teams, competition groups and changing facilities remain characterised by male-female segregation, which intensified their sense of being excluded. Furthermore, it is not just sport per se that is difficult, as a lack of public acceptance or understanding means that any form of physical activity is fraught with difficulty.

Placing transgender experiences of sport in the context of social exclusion and minority stress theory, a number of important findings emerge from this study. Firstly, the depth of transgender exclusion is palpable. Unlike, for example, ethnic minorities, 
Hargie O., Mitchell, D. and Somerville, I.

transgender people are not 'born into' their minority identity but acquire it later and so do not have an immediate reference and support group. Indeed, from birth, they are allocated a contrasting gender identity which to rectify necessitates dealing with significant and additional psychological, societal and physical stressors. Interviewees experienced a wide range of such stressors within all four of Bailey's (2005) dimensions of exclusion. They suffered relational barriers including the ignorance of sports teachers and sports facility staff and hostility from members of the public; the strength of their stories here indicated that they were still ruminating about these experiences. Indeed no instances of acceptance or belonging in sporting environments emerged from their accounts. For a variety of reasons, they were forced to abandon involvement in team sports and opt for individual activities, thereby reducing the potential for relational inclusion. They experienced spatial exclusion, in that the social and economic distances between them and other groups remained high. This reduced their opportunities for networking with others, thereby negatively impacting upon their stock of social capital. Since social capital can serve to foster the creation of new identities or affirm an existing aspect of self (Weller, 2010), this exclusion also undoubtedly impacted upon the gender transition and identity affirmation process. Some interviewees reported that they had to take lower income jobs, while incurring the increased expenses involved in transitioning, further reducing their capacity to participate in sport.

They also experienced functional exclusion through missing out on the capacity to benefit from the knowledge, understanding and skills developed through sports participation. Several interviewees gave specific examples of sports they wished to participate in (e.g. canoeing, ballet, swimming) and which they believed would have developed and fulfilled them as individuals, but from which they felt excluded. Their accounts here indicated a strong sense of rejection sensitivity. Finally, they experienced a distinct loss of power, and reduced personal control in sporting environments. As a result of their non-involvement in sport they 
Hargie O., Mitchell, D. and Somerville, I.

suffered from a lack of fitness and broken exercise habits, and this affected their confidence during the transition process. They felt exposed in having to use shared changing rooms and showers. A further indication of this sense of disempowerment was the internalisation of negative social attitudes about their minority group as expressed in the belief that they could be 'violating' others just by being in the locker room.

The stories recounted by the interviewees also illustrate how employment and the availability of resources are no guarantee of ability to participate in the key activities of society. Collins and Kay (2014) maintain that poverty is the 'core' of social exclusion because groups who suffer from the prejudices of others tend also to be poor. Moreover, most sport must be paid for. However, Spaaij et al. (2014: 166) argue that this view is unnecessarily reductive, pointing out that 'cultural stigmatization, civil rights violations, institutional discrimination and other social processes all play their part in producing the enforced lack of participation that is experienced by many individuals and groups across the world'. Most conceptualisations of social exclusion understand it as a process inflicted on people as much as a condition experienced by people, an emphasis which is absent when simply financial poverty is prioritised (Barnes, 2005; Levitas, 2006).

Some interviewees expressed the view that transgender people tend to have low incomes, thereby supporting the link between poverty and social exclusion. However, while lack of money may have contributed to their exclusion from sport, it was not the main factor. Rather, they suffered principally from the 'moral' dimension of social exclusion, through being rejected and stigmatised for being outside the norm (Spaaij et al., 2014). These distal stressors in turn triggered a range of related proximal stressors, which confirms the findings of a meta-analysis of research studies by Pascoe and Richman (2009), that "increased levels of perceived discrimination are associated with more negative mental and physical health" (p. 544), and that this occurs as a result of the stress responses they generate. 
Hargie O., Mitchell, D. and Somerville, I.

Furthermore, the findings also confirm that the facets of social exclusion are both selfsustaining and interconnected (Silver and Miller, 2003; Pierson, 2010). Thus, for transgender people, lack of sporting and physical activity opportunities, and the distal and proximal stressors of prejudice and fear of rejection that they have experienced in sport, compound the psychological stress of gender dysphoria. In terms of minority stress theory, Meyer (2003) highlighted the important distinction between perceptions of the minority person as resilient actor rather than victim. Holding the former interpretation shifts the weight of responsibility for oppression and victimisation from society to the individual. Failure to cope can then be interpreted as a personal, rather than societal, failure. Such subjective interpretations carry dangers in that they cast the minority individual as someone who must bravely cope with and overcome personal adversity. The contrasting objective view, that the minority person is a victim of discrimination that must be eradicated, aligns with the perspectives of the transgender people in our study.

As this study found, perceived obstacles, levels of fear, and negative experiences in the past, were such that interviewees chose not to attempt to take part in sport and physical activity. Levitas (2006) demonstrates that although the case of someone not wanting to avail of opportunities might seem like a clear case of voluntary exclusion, there is evidence that, in actuality, there may be a range of factors that determine such a response. Their choices in this regard cannot be viewed as entirely voluntary. Our findings indicate that rather than engaging in voluntary exclusion from sporting activities, it was as a result of their negative experiences therein that respondents had decided not to participate.

The demise of sex-segregation in sport is unlikely, and as Love (2014: 382) points out, there exist 'legitimate concerns about advocating integration under conditions of deepseated gender inequality in sport'; women may find empowerment in sport and physical activity settings in which men and sexism are absent. Nevertheless, as Travers (2006: 444) 
Hargie O., Mitchell, D. and Somerville, I.

has argued in relation to her study of lesbian softball leagues in North America, 'The protection of traditional women-only space and the softening of the gender binary to be more transinclusive need not be mutually exclusive'. The evidence in this study points to the potentially transformative impact of measures 'softening' the gender binary in sport for transgender persons: training in transgender issues for sports organisers at school and in sports clubs leading to greater respect for transgender people's self-identification; cubicles in changing areas; and increased public awareness of transgender issues. In the meantime, the reality persists that the self-exclusion of individuals that visibly deviate from gender norms from sporting and other settings, as evidenced in this study, simply ensures that their presence remains remarkable for sports organisers and the general public, and, contributes to the ongoing unwelcoming nature of those settings.

\section{Funding}

The research detailed here formed part of a major Northern Ireland Government funded research project by the authors, entitled Social Exclusion and Sport in Northern Ireland. This funding was provided by the Office of the First Minister and Deputy First Minister, Equality Directorate Research Branch.

\section{Acknowledgements}

The authors would like to thank the leaders and members of Focus: The Identity Trust for their generous assistance with this research.

\section{References}


Hargie O., Mitchell, D. and Somerville, I.

Abrams D, Hogg M and Marques J (eds) (2005) The Social Psychology of Inclusion and Exclusion. Philadelphia: Psychology Press.

Alvesson M and Skoldberg K (2009) Reflexive Methodology: New Vistas for Qualitative Research. London: Sage.

Anderson E (ed) (2013) Sport, Masculinities and Sexualities. Abingdon: Routledge.

Bailey R (2005) Evaluating the relationship between physical education, sport and social inclusion. Educational Review 57(1): 71-90.

Barnes M (2005) Social Exclusion in Great Britain: An Empirical Investigation and Comparison with the EU. Aldershot: Ashgate.

Brackenridge C, Alldred P, Jarvis A, et al. (2008) A Literature Review of Sexual Orientation in Sport: A Summary. Centre for Youth Sport and Athlete Welfare, Brunel University. Available at: https://www.sportengland.org/media/174173/so-summary-final1.pdf (accessed 10 April 2015).

Burchardt T, LeGrand J and Piachaud D (2002a) Introduction. In: Hills J, LeGrand J and Piachaud D (eds) Understanding Social Exclusion. Oxford: Oxford University Press, pp.1-12.

Burchardt T, LeGrand J and Piachaud D (2002b) Degrees of exclusion: Developing a dynamic, multidimensional measure. In: Hills J, LeGrand J and Piachaud D (eds) Understanding Social Exclusion. Oxford: Oxford University Press, pp.30-43.

Buzuvis E (2011) Transgender student-athletes and sex-segregated sport: Developing policies of inclusion for intercollegiate and interscholastic athletics. Seton Hall Journal of Sports and Entertainment Law, 21(1). Available at:

http://scholarship.shu.edu/cgi/viewcontent.cgi?article=1006\&context=sports_entertain ment (accessed 13 January, 2015). 
Hargie O., Mitchell, D. and Somerville, I.

Caudwell J (2014) [Transgender] young men: gendered subjectivities and the physically active body. Sport, Education and Society. DOI:10.1080/13573322.2012.672320.

Caudwell J and Browne K (eds) (2013) Sexualities, Spaces and Leisure Studies.

Abingdon: Routledge.

Cavanagh S and Sykes H (2006) Transsexual bodies at the Olympics: The International Olympic Committee's Policy on transexual athletes at the 2004 Athens summer games. Body \& Society 12(3): 75-102.

Clark S and Paechter C (2007) Why can’t girls play football? Gender dynamics and the playground. Sport, Education and Society. DOI: 10.1080/13573320701464085.

Coalter F (2007) A Wider Social Role for Sport. Who's Keeping the Score? Abingdon: Routledge.

Collins M and Kay T (2014) Sport and Social Exclusion $2^{\text {nd }}$ edition. Abingdon: Routledge.

Dagkas S and Armour K (eds) (2012) Inclusion and Exclusion through Youth Sport. Abingdon: Routledge.

Dionigi R (2006) Competitive sport as leisure in later life: negotiations, discourse, and aging. Leisure Sciences: An Interdisciplinary Journal. 28(2): 181-196.

Federico B, Falese L, Marandola D and Capelli G (2013) Socioeconomic differences in sport and physical activity among Italian adults. Journal of Sports Sciences. 10.1080/02640414.2012.736630.

Effrig J, Bieschke K and Locke B (2011) Examining victimization and psychological distress in transgender college students. Journal of College Counseling 14(2): 143-157.

GLAAD (2014) Media Reference Guide $9^{\text {th }}$ Edition: Transgender Issues. Available at: http://www.glaad.org/sites/default/files/GLAAD\%20MRG_9th.pdf (accessed 22 March 2015). 
Hargie O., Mitchell, D. and Somerville, I.

Grossman AH and D'Augelli AR (2007) Transgender youth and life-threatening behaviors.

Suicide and Life-Threatening Behavior 37(5): 527-537.

DOI:10.1521/suli.2007.37.5.527

Halberstam J (1998) Female Masculinity. Durham, NC: Duke University Press.

Hansson U and Depret M (2007) Equality Mainstreaming: Policy and Practice for

Transgender People. Belfast, Institute for Conflict Research. Available at:

http://www.ofmdfmni.gov.uk/transgenderequality22may07.pdf (accessed 12 April, 2015).

Hargie O, Somerville I and Mitchell D (2015) Social Exclusion and Sport in Northern Ireland. Jordanstown, Northern Ireland: Ulster University.

Hargreaves J and Anderson E (eds) (2014) Routledge Handbook of Sport, Gender and Sexuality. Abingdon: Routledge.

Kauer K and Krane V (2013) Sexual identity and sport. In: Roper E (ed) Gender Relations in Sport. Rotterdam: Sense Publishers, pp. 53-72.

Kenagy G (2005) Transgender health: Findings from two needs assessment studies in Philadelphia. Health \& Social Work 30(1): 19-26.

Keogh P, Reid D and Weatherburn P (2006) Lambeth LGBT Matters: The Needs and Experiences of Lesbians, Gay Men, Bisexual and Trans Men And Women in Lambeth. Lambeth: Sigma Research. Available at: http://www.sigmaresearch.org.uk/files/report2006c.pdf (accessed 10 March, 2014).

Lake R (2013) ‘They treat me like I'm scum': Established-outsider relations in a British tennis club. International Review for the Sociology of Sport, 48(1): 112-128.

Le Blanc A, Frost D and Wight R (2015) Minority stress and stress proliferation among same-sex and other marginalized couples. Journal of Marriage and Family 77: 40-59. 
Hargie O., Mitchell, D. and Somerville, I.

Levitas R (2006) The concept and measurement of social exclusion. In: Pantazis C, Gordon D and Levitas R (eds) Poverty and Social Exclusion in Britain. Bristol: Policy Press, pp. 123-160.

Love A (2014) Transgender exclusion and inclusion in sport. In: Hargreaves J and Anderson E (eds) Routledge Handbook of Sport, Gender and Sexuality. Abingdon: Routledge, pp. 376-383.

Lucas-Carr C and Krane V (2011) What is the $T$ in LGBT? Supporting transgender athletes through sport psychology. The Sport Psychologist 25(4): 532-548.

Lucas-Carr C and Krane V (2012) Troubling sport or troubled by sport? Journal for the Study of Sports and Athletes in Education 6(1): 22-44.

Mathy RM (2002) Transgender identity and suicidality in a nonclinical sample: Sexual orientation, psychiatric history, and compulsive behaviors. Journal of Psychology \& Human Sexuality 42(4): 89-101.

Meyer IH (2003) Prejudice, social stress, and mental health in lesbian, gay, and bisexual populations: Conceptual issues and research evidence. Psychological Bulletin 129(5): 674-697. DOI:10.1037/0033-2909.129.5.674

Meyer IH and Northridge ME (eds) (2007) The Health of Sexual Minorities: Public Health Perspectives on Lesbian, Gay, Bisexual and Transgender Populations. New York: Springer.

Pascoe EA and Richman LS (2009) Perceived discrimination and health: A meta-analytic review. Psychological Bulletin 135(4): 531-554. DOI: 10.1037/a0016059

Pierson J (2010) Tackling Social Exclusion second edition. Abingdon: Routledge. Putnam R (2000) Bowling Alone: The Collapse and Revival of American Community. New York: Simon and Schuster. 
Hargie O., Mitchell, D. and Somerville, I.

Rankin S, Weber G, Blumenfeld W and Fraze S (2010) 2010 State of Higher Education for LGBT People. Charlotte, NC: Campus Pride.

Reeser J (2005) Gender identity and sport: Is the playing field level? British Journal of Sports Medicine 39(10): 695-699.

Scraton S and Flintoff A (eds) (2002) Gender and Sport: A Reader. Abingdon: Routledge.

Semerjian TZ and Cohen JH (2006) 'FTM means female to me': transgender athletes performing gender. Women in Sport and Physical Activity Journal 15(2): 28-43.

Silver H and Miller S (2003) Social exclusion: the European approach to social disadvantage. Indicators 2(2): 5-21.

Smith M, Cuthbertson S and Gale N (2012) Out for Sport: Tackling Transphobia in Sport. Transgender Specific Companion Report. Edinburgh, Scotland: Equality Network. Available at: http://www.equality-network.org/wpcontent/uploads/2013/03/Transgender-specific-companion-report.pdf (accessed 19 January 2015).

Spaaij R, Magee J and Jeanes R (2014) Sport and Social Exclusion in Global Society. Abingdon: Routledge.

Sports Council Equality Group (2013) Transsexual People and Competitive Sport: Guidelines for National Governing Bodies of Sport. London: Sports Council Equality Group. Available at: http://www.sportni.net/sportni/wpcontent/uploads/2013/03/TranssexualPeopleandCompetitiveSportGuidanceforNationa 1GoverningBodies.pdf (accessed 10 April 2015).

Stalsberg R and Pedersen A (2010) Effects of socioeconomic status on the physical activity in adolescents: A systematic review of the evidence. Scandinavian Journal of Medicine \& Science in Sports. DOI: 10.1111/j.1600-0838.2009.01047.x. 
Hargie O., Mitchell, D. and Somerville, I.

Sullivan CF (2011) Gender verification and gender policies in elite sport: Eligibility and 'fair play'. Journal of Sport and Social Issues. DOI: 10.1177/0193723511426293.

Sykes H (2006) Transsexual and transgender policies in sport. Women in Sport and Physical Activity Journal, 15(1): 3-13.

Sykes H (2011) Queer Bodies: Sexualities, Genders and Fatness in Physical Education. New York: Peter Lang.

Symons C and Hemphill D (2006) Trangendering sex and sport in the Gay Games. In:

Caudwell, J (ed) Sport, Sexualities and Queer/Theory. Abingdon: Routledge, pp. 109128.

Symons C, Sbaraglia M, Hillier L and Mitchell A (2010) Come Out to Play: The Sports Experiences of Lesbian, Gay, Bisexual and Transgender (LGBT) People in Victoria. Institute of Sport, Exercise and Active Living; School of Sport and Exercise Science, Victoria University, Melbourne. Available at: http://www.glhv.org.au/files/ComeOutToPlay.pdf (accessed 12 October, 2014).

Tagg B (2012) Transgender netballers: ethical issues and lived realities. Sociology of Sport Journal 29(2):151-167.

Travers A (2006) Queering sport: Lesbian softball leagues and the transgender challenge. International Review for the Sociology of Sport. DOI: 10.1177/1012690207078070.

Travers A and Deri J (2011) Transgender inclusion and the changing face of lesbian softball leagues. International Review for the Sociology of Sport 41(3-4): 431-446.

Tunstall R (2011) Social Housing and Social Exclusion 2000-2011. London, LSE: Centre for Analysis of Social Exclusion. Available at: http://sticerd.lse.ac.uk/dps/case/cp/CASEpaper153.pdf (accessed 24 November 2014). von Braun J and Gatweiler F (eds) (2014) Marginality: Addressing the Nexus of Poverty, Exclusion and Ecology. New York: Springer. 
Hargie O., Mitchell, D. and Somerville, I.

Wahlert L and Fiester A (2012) Gender transports: Privileging the 'natural' in gender testing debates for intersex and transgender athletes. The American Journal of Bioethics. DOI: $10.1080 / 15265161.2012 .683750$.

Weller S (2010) Young people's social capital: complex identities, dynamic networks. Ethnic and Racial Studies 33(5): 872-888.

Whittle S, Turner L and Al-Alami M (2007) Engendered Penalties: Transgender and Transsexual People's Experiences of Inequality and Discrimination. London: The Equalities Review. Available at: http://www.pfc.org.uk/pdf/EngenderedPenalties.pdf (accessed 10 March 2014). 